\title{
MIRACULUM Y MALEFICIUM. ALGUNAS REFLEXIONES SOBRE LAS MUJERES SANTAS DE LA EDAD MEDIA EN EUROPA CENTRAL*
}

\section{Gábor Klaniczay}

En el año 1276, durante las verificaciones sobre la santidad de la princesa Margarita, hija del ya difunto rey Béla IV, en la Isla de los Conejos cerca de Buda (también conocida como la Isla de la Virgen María y poco después renombrada como Isla Margarita), la abadesa dominica Margarita, una de las testigos del convento real de las dominicas y sobrina de la princesa Margarita, contó el milagro que habría obrado su santa tía y que detallamos como sigue:

Aquel día, cuando la virgen Margarita estaba sumergida profundamente en su oración, uno de los huesos de su espalda se desplazó y le produjo un fuerté dolor. La madre superiora y algunas monjas estaban muy excitadas por lo sucedido y buscaban un remedio para curarla. Yo pensaba para qué tanta agitación por un remedio para esta monja, lo encontré simplemente ridículo y me reía por dentro. En ese mismo instante sentí un fuerte dolor en mi espalda, exactamente en el mismo lugar donde le dolía a la monja. Sin dudarlo, me tiré a los pies de la virgen Margarita y le conté mis pensamientos y lo que había sucedido después. Le confesé mi pecado y le rogué que me procurase alivio (quod parceret mihi). Cuando ya le había contado todo esto, la virgen Margarita me dijo: «que el Señor te redima», e inmediatamente mis dolores desaparecieron'.

Este pequeño relato - aunque en absoluto representativo de los 84 milagros de santa Margarita ${ }^{2}$ - es muy instructivo acerca de los pequeños cinis-

* Wissenschaftskolleg-Jahrbüch, 1990/1991, pp. 224-252.

1 Vilmos FrAKNót (ed.): «Inquisitio super vita, conversatio et miraculis beatae Margarethae virginis, Bellae IV. Hungarorum regis filiae, sanctimonialis monasterii virginis gloriosae de insula Danubii, Ordinis Praedicatroum, Vesprimis diocesis», en Monumenta Romana episcopatus Vesprimiensis (desde aquí MRV). Budapest, 1896, tomo 1, pp. 182-183; la misma historia contada por otras monjas: pp. 187, 192, 275.

${ }^{2}$ En relación con las indicaciones esenciales sobre Margarita, véase también mis estudios (que, dicho aparte, han servido como punto de salida para el presente artículo): $\alpha$ Leyendas como es 
mos y las escondidas hostilidades a las que estuvo expuesta en el convento la elegida princesa de familia real (candidata ya en vida a la canonización) por parte de sus hermanas, también de origen aristocrático, pero menos felices; el relato nos da una idea del concepto de milagro que se tenía en la Hungría del siglo XIII. De hecho podríamos preguntarnos: ¿se trata realmente de un milagro el acontecimiento relatado más arriba o más bien es un caso de brujería, un maleficium? Alguien que posee capacidades sobrenaturales puede leer pensamientos y descubre así un pequeño insulto, castiga a la culpable causándole un dolor corporal y, después. de que se le niega alivio y de que la malhechora le muestra su arrepentimiento por lo ocurrido, está dispuesta a remediar el daño mágico que ha sufrido esa persona. Esta secuencia morfológica es una de las muestras básicas más frecuentes en las inumerables historias relatadas por testigos de procesos de brujería de la temprana Edad Moderna sobre embrujamientos y sus consiguientes intentos de curación. Cuando es posible un acuerdo amigable con la bruja, entonces el maleficium puede remediarse inmediatamente y se puede renunciar a un curandero profesional o cazador de brujas, e incluso a pasos judiciales.

Se podría aducir que el milagro de Margarita tuvo lugar con la colaboración anunciada de los poderes divinos. Además, la bien calculada simetría del carácter del pecado y del arte de castigar o el hecho de que se obtenga el perdón solamente después de mostrar públicamente el arrepentimiento representa para los relatos de milagros una importante y característica ampliación pastoral-pedagógica ${ }^{3}$, que falta por completo en las descripciones populares de embrujamientos (maleficia). Sin embargo, las concordancias tipológicas son muy confusas.

Para reforzar aún más nuestra sospecha, quisiera comentar brevemente otros tres milagros de santa Margarita de Hungría que también fueron discutidos dentro del marco de las verificaciones ya mencionadas. Los primeros dos ejemplos ilustran su poder sobre los elementos. Cuando de pequeña vivía en otro convento de monjas, en el convento de Santa Caterina en Veszprém ${ }^{4}$, una vez mencionó su urgente deseo de que los dos monjes do-

trategia de vida: santas femeninas en Europa central durante la Edad Media tardía en Gábor KLANICZay, Heilige, Hexen, Vampire. Vom Nutzen des Übermatürichen (Santas, brujas, vampiras, De la utilidad de lo sobrenatural), Berlín, Wagenbvach, 1991, pp. 15-16, anotación 4, 1fneas 51-54. Los relatos sobre milagros fueron de Elemér Lovas, Arpáaházi Boldog Margit élete, Budapest, Szent István Társulat, 1940, pp. 276-337.

${ }^{3} \mathrm{~L}$ as funciones pedagógicas de los relatos sobre milagros en la alta Edad Media son tratadas en:

Aaron GUREVICH, Medieval popular culnure. Problems of belief and perception (La cultura medieval popular. Problemas de creencias y percepeión), traducido por János M., Bak y Paul A. Hollingsworth, Cambridge/Paris, Cambridge University Press/Editions de la Maison des Sciences de I'Homme, 1988, pp. 39-76.

4 Jenó GutheIl. Az Arpádkori Vešspém. Budapest, 1981, pp. 166-177; Mlona KIRaLy. Arpádházi sżent Margit és a sziget. Budapest, Szent István Társulat, 1979, pp, 43-59. 
minicos que estaban de visita siguiesen con sus prédicas. Cuando éstos se negaron a quedarse, ella dijo:

«Rezaré a Dios para que haga caer mucha lluvia, asi no podreís partir.» Ellos respondieron que ninguna lluvia les podría detener, pero la bienaventurada Margarita, que tenía quizás diez ăoos de edad en aquella época, entró en la iglesia y pidió la lluvia a Dios. Poco después empezó a llover de tal forma que los dos monjes tuvieron que regresar sin poder partir ${ }^{5}$.

En otra versión de la historia se cuenta que hizo que se rompiese una rueda de carro, con la misma intención y con el mismo resultado ${ }^{6}$ Muchos años más tarde su confesor, el padre Marcellus, provincial de los dominicos húngaros ${ }^{7}$, tuvo que experimentar en su propio cuerpo el poder maravilloso que poseía Margarita sobre Jos elementos:

Vine desde Gran a este convento y la hermana Margarita me dijo: «Casi nos hubieramos hundido, porque el Danubio había crecido tanto que, de haber estado alli en frente, el agua nos hubiera cubierto totalmente», - «Venga, venga», contesté, «no lo puedo creer». Entonces ella dijo: «Señor Jesucristo, muéstrale a este abad que estoy diciendo la verdad para que me creas. Y el agua empezó a crecer con tanta velocidad que tuve que huir y subir a los muros que rodeaban el convento... 8 .

El Danubio que rodeaba la zona santa del convento de Margarita ${ }^{9}$ también juega un rol importante en el cuarto milagro de castigo que quiero citar aqui ${ }^{10}$, aunque no como "médium» de un acontecimiento maravilloso, sino como área liminar o de traspaso ${ }^{11}$ que, al ser sobrepasada permite llegar a

${ }^{5}$ MRV, p. 174; cf. pp. 179-180, 221

${ }^{6} \mathrm{MRV}, \mathrm{pp}, 169,218$.

${ }^{7}$ Miklos PFEIFER. Die ungarische Dominikanerprovinz von ihrer Gründung bis zur Tatarenwïstung 1241-1242 (La provincia hüngara de los dominicos desde su fundación hasta la devastación por los tártaros). Zürich, 1913; Elemér MALyusz, *Arpádhízi Boldog Margit (A magyar egyháżi müveltség problémája)m, en Emlékkönyv Károlyi A pód születése nyolcvana. dik fordulojínak ünnepére, Budapest, 1933, pp. 341-384; Elemér LovAs, «Arpádházi B. Margit elso eletrajzának irója - Marcellus», en A Pannonhaimai Föapátság Föiskolai Evkönyve 19.40/1941, pp. 21-85.

${ }^{8}$ MRV, pp. 280-281; otros relatos, pp, 183, 186, 191-192, 223, 242-243.

${ }^{9}$ Me he ocupado más detenidamente del contexto espacial de los relatos de los milagros de Margarita en mi estudio: *Il monte die San Gherardo e l'isola di Santa Margherita: gli spazi della santità a Buda nel Medioevom, en Sofía Bozsch Gajano - Lucetta Scaraffia (eds.). Luoghi sacri e spazi della santità, Turín, Rosenberg \& Sellier, 1990, pp. 267-284.

10 Vita beate Margarite de Ungaria Ordinis Predicatorum, en P. Böle Kornél, Arpádházi Boldog Margit szenntéavatási ligye és a legösibb latin Margit-legenda, Budapest, Stephancum, 1937, pp. 37-38.

"La importancia ritual liminar de estas zonas es destacada en fa antropología cuftural: p.ej. 
la esfera de acción de los poderes milagrosos emitidos por las reliquias de santa Margarita.

Érase una vez un hombre honorable de nombre Pondsa. Vivía en la diócesis de Veszprém. Este hombre devoto visitaba regularmente la tumba de la virgen Margarita. Una vez dijo a sus acompañantes: «iHagamos una peregrinación a santa Margarita!». A sus acompañantes no les agrado esta propuesta y argumentaron en contra. Como él era laico y fácilmente influenciable, no fue difícil hacerle cambiar de opinión. Dos días más tarde les dijo a los mismos amigos: «Por qué no vamos a la isla de Nuestra Señora, la Virgen María, y damos un paseo». En este momento ya había olvidado su otra propuesta de peregrinación. Pero nada más sentarse en el barco, sintió un dolor muy fuerte en su mano izquierda. Antes de haber cruzado el Danubio los dolores se hicieron tan fuertes que su mano, e incluso todo el brazo hasta la espalda, estaban como entumecidos y sin sentido; no podía ni levantar ni bajar el brazo. En seguida se dio cuenta de que era un castigo por su pecado y lleno de miedo y temblores se encaminó hacia la tumba de santa Margarita. Pero no encontró la misericordia y el perdón del creador: aún no estaba completamente libre del pecado de la duda. Con el corazón roto, sumiso y lamentándose pidió el perdón a la virgen con estas palabras: « $ز \mathrm{Oh}$, Margarita, tú, que te has consagrado a Dios! Todos aquellos que vienen de las más diversas partes del país, atormentados por cualquier enfermedad o dolor, vuelven a sus casas curados. Cuando dejé mi casa gozaba de buena salud y de buen ánimo, pero ahora, debido a mi poca fe, quizás deberé regresar a mi casa en un estado lamentable y cojo, para la eterna vergüenza de mí mismo y de mi familia». Mientras tanto sus dolores eran cada vez más fuertes y sus lágrimas de arrepentimiento cayeron sobre la tumba. Rezaba sin parar pidiendo por la gracia de una curación. Con este deseo que crecía cada vez más, también la curación se acercaba cada vez más y, cuando acabó de cantar las vísperas, estaba completamente curado. En voz alta elogí́ la magnitud de Dios, los méritos de la hermana Margarita y el éxito de sus perseverantes oraciones suplicantes.

Estos cuatro milagros obrados por santa Margarita y explicados aquí detalladamente presentan dos aspectos raros, aunque no totalmente desconocidos, no sólo del amplio género de recopilaciones de milagros de la Edad Media en general, sino incluso dentro de la categoría de milagros de

Victor y Edith TuRner, Image and Pilgrimage in Christian Culture. Anthropological Pers. pectives, Nueva York. Columbia University Press, 1978; Victor TURNER, The Rirual Process. Structure and Anti-Structure, segunda edición The L.H. Morgan Lectures, 1966, Ithaca/Londres, Comell University Press, 1977. 
castigo $^{12}$. En estos ejemplos los afectados no son las personas que han cometido pecados contra una comunidad o institución que se encuentra bajo la protección del correspondiente santo; tampoco se trata de una vulneración de tiempo y espacios santos o de mandamientos morales; al contrario, más bien ocurre que Santa Margarita (o sus reliquias) pone en marcha el mecanismo del castigo milagroso no con algún objetivo altruista, sino porque ha sído ofendida personalmente o para obtener un objetivo puramente personal.

Después de esta breve ojeada a la ambigüedad de los poderes sobrenaturales de las santas en la Edad Media, ampliamente ocultada por las intenciones propagandísticas y hagiográficas de la mayoría de las recopilaciones de milagros, quisiera reflexionar aquí sobre un tema mucho más amplio (tal como lo deja intuir el título de mi artículo) del que me interesa sobre todo el problema de la relación histórica entre las santas y las brujas. Abordaré cuatro ámbitos temáticos diferentes.

El primer tema (al que me quiero dedicar algo más extensamente) se refiere a la caracterización de lo que se podría denominar la *corte celestial» de santa Margarita y de una docena más de princesas santas del siglo xIII. Se trata aquí de una mezcla curiosa de santidad dinástica al viejo estilo y de santidad femenina con un estilo nuevo que - junto con algunas otras formas contemporáneas de santidad femenina - ha cambiado radicalmente la imagen medieval sobre el acceso a los poderes sobrenaturales de las mujeres.

Luego quiero aludir brevemente a cómo ha contribuido esta emancipación religiosa femenina en la baja Edad Media, cuyos primeros pasos estuvieron vinculados a las santas princesas de la Europa central, a que la imagen aterradora de las brujas, que surgía en el siglo Xv, haya sido presentada esencialmente como figura femenina.

Esta argumentación puede ampliarse con otros dos grandes ámbitos temáticos: por un lado, el conflicto histórico y el contexto de alternancia entre las formas de imaginar las creencias y funciones relacionadas con la santidad y la brujería que datan de la antigüedad tardía, y, por otro, la comparación morfológica y tipológica de milagros y embrujamientos.

Con este planteamiento excesivamente amplio, en el que se quieren abordar en todo caso las diferentes posibilidades de explicación histórica y teorética de la ya mencionada ambigüedad de la santidad femenina en la Edad Media y su efectividad milagrosa, no voy a poder entrar en detalles de

${ }^{12}$ Cf. GuREvich, Medieval popular culture, pp. 46-49; Pierre-André Sical: «Un aspect du culte des saints: le châtiment đivin d'après la littérature hagiographique du Midi de la Frances, en La Religion populaire en Languedoc du XII siècle à la moitié du XV siècle, Cahier de Fanjeaux, núm. 11. Toulouse, Privat, 1975; fdem, Lhomme et le miracle dans la France médievale (XI-XII siècle), Paris, Cerf, 1985. 
contexto histórico ${ }^{13}$ en la Europa central, ni del culto a la santidad ${ }^{14}$, ni la creencia en milagros ${ }^{15}$, ni en las persecuciones de la Edad Media y de la temprana Edad Moderna.

Con mis reflexiones intento yuxtaponer diferentes tipos de desarrollo histórico (política de prestigio dinástica, movimientos religiosos, formas de creencias populares, tipos narrativos), cuya articulación y dinámica me parecen ejemplificadores.

«eus vellem, quod ego essem una ancilla pauperi potius, quam filia regis, quia magis possem servire Deo, $»$ Este suspiro de santa Margarita, citado por la también hermana Cándida en relación con el proceso de canonización en el año $1276^{16}$, nos transmite una imagen impresionante y emblemática del ideal de santidad femenina y de realeza, por el que se dejaron guiar — así podemos suponer- aproximadamente una docena de princesas religiosas en las cortes de Europa central en los siglos XIII y XIV. A pesar de ello no debemos entender el deseo de la princesa Margarita, aunque hubiese correspondido a sus propias convicciones, vinculadas a las novísimas tendencias de la religiosidad del siglo XII, como una descripción acertada y apropiada de la característica religiosa de este modelo de santidad que abría una perspectiva de vida novísima a las princesas de aquella época. Este «movimiento feministas aristocrático estaba naturalmente estrechamente vinculado a las tendencias religiosas básicas de los siglos XII y XIII, donde se hicieron sentir (en la cultura mundana y de corte ${ }^{17}$, en la ascensión del culto a la Virgen María ${ }^{18}$,

${ }^{13}$ Una imagen general de Bálint Hóman, Geschichte des ungarischen Mittelalters (Historia de la Edad Media húngara), traducido por Hildegard Roosz-Lothar Saczek, Berlín, De Gruyer 1940-1943, tomo 2 (De finales del siglo XI hasta los comienzos de la casa de Anjou); Gyula MoRAVEsIK. Byzantium and the Magyars, Amsterdam, Hakkert, 1970. La magnifica sintesis nueva de Jenö Szucs: Az utólsó Arpádok desgraciadamente no ha sido publicada ni en lengua húngara.

${ }^{14}$ Una evaluación todavía muy útil de la histografía del culto a la santidad la ofrece Frantisèk Graus, Volk, Herrscher und Heiliger im Reich der Merowinger (Pueblo, soberanos y santos en el imperio de los merovingios), estudios para la hagiografía de la época de los merovingios, Praga, Nakladatelstvi Ceskoslovenské akademie ved, 1965. Bibliografía en Stephen Wuson (ed.): Saints and their Cults: Studies in Religious Sociology, Cambridge, Cambridge University Press, 1983. De las nuevas monografias destacaria los siguientes: Peter BRowN, The Cult of Saints. Its Rise and Function in Latin Christianity, Chicago, The University of Chicago Press, 1981; Michael GoopiCH, Vita Perfecta: The Ideal of Sainthood in the Thirteenth Cenrury (Monografías para la historia de la Edad Media, 25), Stuttgart, Hiersemann, 1982; André VAUCHE2, La sainteté en Occident aux dernières siècles du moyen äge. D'après les procès de canonisation et les documents hagiographiques, Roma, École Française de Rome, 1981.

${ }^{15}$ Ronald C. Finucane, Miracies and Pilgrims, Popular Beliefs in Medieval England, Londres, J.M. Den \& Sons, 1977; Benedicta WARD, Miracles and the Medieval Mind, Londres. Scolar, 1982; Sigal, Lhomme et le miracle.

${ }^{16} \mathrm{MRV}, \mathrm{p} .261$.

${ }^{17}$ Georges Duby, The Knight, the Lady and the Priest: The Making of Modern Marriage in Medieval France, traducido por Barbara Bray. Nueva York, Pantheon, 1983.

${ }_{18}^{18}$ Marina WARnER: Alonte of All Her Sex: The Myth and the Cult of the Virgin Mary, Nueva York, Knopf, 1976. 
en los movimientos heréticos ${ }^{19}$, en las terceras órdenes de los mendicantes ${ }^{20}$ los crecientes esfuerzos de las mujeres por actuar más activamente en las diversas áreas de la vida religiosa. Lo que me interesa aquí es la cuestión de qué pecularidades resultaban del hecho de que «las siervas más pobres de Cristo ${ }^{21}$ viniesen de los círculos de la familia real.

La pobreza voluntaria de las princesas de Europa central iba a parecer a los contemporáneos como la mayor renuncia heroica posible, porque de todas las mujeres ellas tenían lo máximo que perder. Esto explica también por qué la primera y más famosa representante de este nuevo modelo de santidad, santa Elisabeth de Hungría (1207-1231), hija del rey Andreas II de Hungría y viuda del landgrave Ludwig IV de Turinga, fue canonizada en un tiempo récord y bajo circunstancias suntuosas y profusas sólo cuatro años después de su muerte, por cierto - y en vista de la tensa relación existente entre ellos un hecho sumamente inusualcon el apoyo activo del papa Gregorio IX y del emperador Federico II. Ella se convirtió en una de las santas más adoradas y queridas en todo Europa en la baja Edad Media ${ }^{22}$.

De entre las numerosas otras santas y religiosas representantes femeninas de las dinastías de Europa central queremos mencionar las siguientes: Hedwig von Schlesien (1174/78-1243) ${ }^{23}$, Agnes de Bohemia

${ }^{19}$ Herbert GRUNDMANN: Religiöse Bewegungen im Mittelalter (Movimientos religiosos en la Edad Media), Berlín, 1935 (Darmstadt: WBG, 1970); Kaspar ELM, «La posición de la mujer en la vida monástica, en la semirreligiosidad y en la herejía en la época de santa Elisabetho, en Sankt Elisabeth, Fürstin Dienerin Heilige (Santa Elisabeth, soberana, servidora, santa), Sigmaringen, Thorbecke, 1981, pp. 7-28; Edith PAstToR, La donna nei movimenti religiosi del Medio Evo, Rivista di pastorale liturgica, 19 (1981), pp. 17-30.

${ }^{20}$ Gilles Gerard MeERSsemans, Dossier de l'ordre de la pénitence au xine siècle. Friburgo. Editions universitaires, 1961: idem, en colaboración con Gian Piero PACINI, Ordo fraternitatis: confraternite e pietà dei laici nel Medioevo (Italia sacra, pp. 24-26), Roma, Herder editora y librería, 197

${ }^{21}$ Santa Agnes de Bohemia, p.cj., se ha dado frecuenternente esta autodeterminación, cf. S. Engelbert Grau (ed. com.), Vida y escritos de la santa Clara, Werl/Westf, Dietrich Coelde, 1960.

${ }^{22}$ Para una recopilación de la investigación cf. Santa Elisabeth. Se espera una nueva síntesis del Prof. Dr. Matias Werner que hace tiempo se ocupa del culto a Elisabeth. Cf. eLa Vita de Elisabeth según Dietrich von Apolda como ejemplo de la hagiografía en la baja Edad Median, en Hans PATzE (ed.): Geschichtsschreibung und Geschichtsbewußtsein im späten Mittelalter (Relato y consciencia de la historia en la baja Edad Media), Vorträge und Forschungen XXXI) Sigmaringen: Thorbecke 1987, pp. 523-541; «Flos Ungariae - Gloria TheutoniaePatrona Hassiae. La politización y regionalización del culto a Elisabeths, en Jürgen PETERsOHN (ed.): Politik und Heiligenverehrung im Hochmintelalter (Politica y cultos a los santos en la alta Edad Media) (Reichenau-Tagung 1990-1991) Vortäge und Forschungen, Sigmaringen, Thorbeke, actualmente en vías de publicación.

${ }^{23}$ Joseph GotrschaL.K. St. Hedwig Herzogin von Schlesien (Santa Hedwig Duquesa de Silesia), Köln/Graz, Böhlau, 1964; Ewald WaLTER, Studien zum Leben der kl. Hedwig Herzogin von Schlesien (Estudios sobre la vida de la santa Hedwig Duquesa de Silesia), Stuttgart/Aalen, Konrad Theiss Verlag, 1972; Vita sanctae Hedwigis ducissae Silesiae. Vita maior, vita minor, 
(1205-1282 $)^{24}$, su hermana Ana de Silesia $(1203-1265)^{25}$, cuñada de Hedwig, Margareta de Hungría (1242-1270), dos (de sus hermanas: Kunigunde $(1234-1292)$ y Yolanda $(+1298)^{26}$. viudas ambas de principes polacos, Salomea (1211-1268), viuda del príncipe húngaro Koloman, que más tarde sería rey de Galicia ${ }^{27}, y$, finalmente, la última princesa de los arpades, Elisabeth von Töss $(1292-1338)^{28}$. Desde el punto de vista de Europa central, estas mujeres religiosas constituyen una novedad no sólo porque marcan las nuevas tendencias de religiosidad femenina, sino también en relación con el tipo predominante, hasta entonces, de santidad en esta región, esto es, la santidad de realeza y dinástica. Tras los cultos a los santos fundadores de estados, los conversores y, en el siglo XII, cada vez más también los monarcas caballerescos (Wenzel de Bohemia, Esteban, Emerich y Ladislao de Hungría), la propagación de estas santas dinásticas llevó a una nueva e interesante interpretación y a una ampliación. La explotación secular política del culto a los santos comenzó en varias regiones (así en Silesia, los principados polacos, Turinga y Hesse) tan sólo con las santas dinásticas. Este cambio se podía entender también como expresión de una nueva forma de división del trabajo entre sexos. según la cual ahora era la misión de los miembros femeninos de las dinastías gobernantes conferir a sus familias el prestigio de la santidad y convertirlos de esta forma en una beata stirps $x^{29}$.

genealogia, ed. Aleksander SEMkowicz, en Monumenta Poloniae Historica (a partir de ahora: MPH) IV, pp. 501-665; Wolfgang BraunFEus (ed.), Der Hedwig Codex, Sammlung Ludwig (E) código Hedwig, colección Ludwig), Berlín, 1972.

${ }^{24}$ Walter SETos, Some new sources for the life of Blessed Agnes of Bohentia, Aberdeen, University Press, 1915; Jan Kapitstrán VysKoclL, Legenda blahosiavené Anezky a ctyri listy Sv. Klary, Praga, Universum, 1933: Maria FAssBinder. Die selige Agnes von Prag, Eine königliche Klarissin (La religiosa Agnes de Praga. Una clarisa de la realeza). Werl/Westr. DietrichCoclde, 1957

${ }_{25}$ A. KNoBluch, Herzogin Anna von Schlesien (La Duquesa Anna de Silesia), Breslau, 1865; Vita Annae ducissae Silesia, ed. Aleksander S7emkowics, en MPH, IV, pp. 656-661.

26 Vita et Miracula sanctae Kyngae ducissa Cracoviensis, ed. Wojciech KERTZYNSKI, MPH IV, pp. 662-744; Cf. Jerzy Wrrozumsk1, «La sainteté des femmes dans le mariage en Pologne médiévalew, en, Georges DuBx - Jean Heucun - Michel Roucre (eds.), La femme au moyen âge, Maubeuge, Touzot, 1990, pp. 249-257.

${ }_{27}$ Vita sanctae Salomeae reginae Halicensis, ed. Wojciech KERTZYNSKI, MPH, IV. pp. $770-796$.

${ }_{28}$ Leben der Prinzessin Elisabet von Ungarn (La Vida de la princesa Elisabeth de Hungria), en Ferdinand VETTER. Das Leben der Schwestern zu Töss beschrieben von Elsbet Stagel samt der Vorrede von Johannes Meyer und dem Leben der Prinzessin Elisabet von Ungarn (La Vida de las hermanas Toss, descrita por Elsbet Stagel, incluyendo el discurso de Johannes Meyer y la vida de la princesa Elisabet de Hungria), (Textos alemanes de la Edad Media, VI) Berlín 1906: Maria Puskely, Arpádházi Boldog Erzsébet és a 14. századi misztika, Roma, 1980.

${ }^{29}$ André Vauchez: «Beata stirps: sainteté et lignage en Occident aux xme et xive siécles». en Georges DUBY - Jacques LE GOFF, Famille et parenté dans l'Occident médiéval. Roma, École Française 1977, pp. 397-406. 
Se puede describir ampliamente el momento dinástico de estos cultos de santidad ${ }^{30}$. En lo que se refiere a santa Elisabeth, fueron precisamente varias las dinastías las que la reivindicaron: además de los arpades, por parte paterna $^{31}$, y la dinastía de Andechs-Meran, por parte materna ${ }^{32}$, hay que mencionar sobre todo a Federico Il que no sólo solía hacer referencia al parentesco con ella, sino que también se tomó la molestia de participar personalmente en el año 1236 en Maguncia en la festiva Translatio de Elisabeth ${ }^{33}$. Y finalmente hay que mencionar también en este contexto a la dinastía de Ludwig de Turinga, que creció en importancia en la primera mitad del siglo xII. Ellas se ocuparon de que la aureola de santidad de Elisabeth se traspasase también a su esposo Ludwig. Con el cuñado de Elisabeth, Heinrich Raspe, la dinastía recibió el título imperial en el año 1246, y aunque no nacieron herederos varones, la hija de Elisabeth. Sophía, consiguió, como nata sanctae Elisabeth, fundar una nueva dinastía monárquica, que reinó sobre el land Hesse en el oeste de sus extendidas posesiones hasta finales de la Edad Media ${ }^{34}$.

De forma similar la canonización de santa Hedvigis en el año 1267 fue apoyada no sólo por los piastas de Silesia, sino también por el rey bohemio Przemysl Ottokar II quien tenía la esperanza de cimentar de esta manera sus reivindicaciones por el paif ${ }^{35}$. La rivalidad existente entre las diferentes dinastías en relación con los nuevos cultos es ilustrada también por los esfuerzos por conseguir la canonización de Margarita de Hungría entre los años 1271 y 1276. Aparte del ejemplo que daba el enorme éxito de su tía, santa Elisabeth, el impulso inmediato para esta empresa salió en parte de la ya mencionada canonización de Hedwig en el año 1267 , y en parte de la iniciativa de la princesa Kunigunde en Cracovia, que quería adornar la Pequeña Polonia con una nueva y monárquica santa, o sea, con su cuñada, la recién fallecida reina Salomea. Esta era la viuda del rey de Galicia, Koloman (+1241), el hermano del padre de Kunigunde y Margarita, el rey Béla IV (nacido

${ }^{30}$ He analizado estos momentos dinásticos en mi estudio «La santidad dinástica y de realeza en Hungrías, en Petersohn, Politik und Heiligenverehrung (Política y adoración de los santos).

${ }^{31} \mathrm{Cf}$. Innozenz TAKÁCS, «La Adoración de santa Elisabeth en Hungria», Franziskanische Studien 18, Estudios francisanos, 1931, pp. 242-258; Ilona Sz. Jönas, Arpad-házi Szzent Erzsébet, Budapest, Akadémiai, 1986, pp. 178-188. M. Werner ha recopilado una documentación muy bella en eFlos Ungariae - Gloria Theutoniae - Patrona Hassiaew.

32 Vita Sancroe Hedvigism o, 515; Soecykyn Genealoye Sancte Hedvigis quondam ducisse Slesie, en Vita Sanctae Hedvigis, pp. 642-651; cf. Gottschalk, Santa Hedvigis, pp. 18-19.

${ }^{33}$ Heimut BeumanN, aFederico II y santa Elisabeth. Con motivo de la visita del emperador en Marburg el día 1 de mayo de 1236m. Sankt Elisabeth (Santa Elisabeth), pp. 151-166.

${ }^{34}$ Heinrich RUCKERT (ed.), Das Leben des hl. Ludwig, Landgrafen von Thüringen, Gemahls der hl. Elisabeth, nach der lateinischen Urschrift ubersetzt von Friedrich Ködiz von Saalfeld (La vida del santo Ludwig, landgrave de Turinga, esposo de la santa Elisabeth, seguin el texto original en latín, traducido por Friedrich Ködiz von Saalfeld), Leipzig, 1851: Sankı Elisabeth, pp. $373-374$.

${ }^{35}$ Gotrschalk. St. Hedwig, pp. 274-283. 
en 1206 , reinó de 1235 hasta 1270$)^{36}$. Estos esfuerzos - finalmente sin éxito- fueron también presenciados entre otros por su hermano, el nuevo rey húngaro Esteban V (nacido en 1239, rein6 de 1270 hasta 1272) quien justo en esta época, o sea en agosto del 1270 , visitó Cracovia ${ }^{37}$. No es de sorprender que inmediatamente tomase las necesarias medidas para conseguir un examen papal para la canonización de Margarita, que había fallecido en enero de aquel año $1270^{38}$.

Las motivaciones dinásticas traslucen también en las leyendas conservadas sobre estas santas; por ejemplo, en la leyenda sobre santa Margarita hay un párrafo largo en el cual se describe su adoración por sus «antecesoras santas y donde se toma casi cada uno de los elementos de sus virtudes como ideal a seguir ${ }^{39}$. Un papel muy especial tenía naturalmente santa Elisabeth, quien representaba un patrón de santidad nuevo y que podían seguir prácticamente todas las princesas santas siguientes ${ }^{40}$. Quisiera caracterizar este modelo con la metáfora de la «corte celestial», un motivo totalmente de moda de las representaciones iconográficas de la coronación de la Virgen María en la baja Edad Media ${ }^{41}$.

Las princesas, las reinas o las viudas de reyes santas intentaban en un principio convertir su inmediato entorno palaciego en correspondencia con los principios celestiales. También en esto Elisabeth fue la primera. Podemos suponer que su estricto confesor Konrad von Marburg (que fue considerado en tiempos del landgrave Hermann I como especialmente derrochador y mundano) tenía que agradecer su especial autoridad en la corte de Turingia sobre todo al juramento del esposo de Elisabeth, Ludwig, de participar en una cruzada. Las estrictas reglas de las actividades religiosas de la joven princesa sirvieron al igual que la aplicación de las capacidades caballerescas y militares del esposo para el santo objetivo de una cruzada - ambos eran la expresión de una disciplina religiosa que se imponía a una corte monárquica- ${ }^{42}$. El estilo de vida de Elisabeth, su atuendo einusual y chocantementen poco cortesano, su rechazo a comer alimentos que habían sido obtenidos por explotación (de la iglesia o de los pobres) sometió la vida cotidiana en la corte a la justicia divina. En

36 Vita Sanctae Salomeae, pp. 784, 788, 791.

37 Gyula PAuL.ER: A magyar nemzet tönénete, Budapest, Athenaeum 1898, II, p. 282.

38 Vina beate Margarite, pp. 36-37.

${ }^{9}$ Vita beate Margarite, pp. 21-22.

${ }^{40}$ Esta imitación la documento en: «Leyendas como estrategia de vidas (ef. nota 2).

${ }^{41}$ Daniel Russo, «La cour céleste dans l'iconographie italienne des derniers siècles du moyen âges, Mémoires de l'Académie de Vaucluse, 7 serie, 6 (1985), pp. 287-304; cf. Philippe VERDIER, Le couronnement de la Vierge: les origines et les premiers dévoloppements d'un thème inconographique, Montreal/París, Institut d’études médiévales/Vrin, 1980.

${ }^{42}$ Fred Schwind: KEl landgraviato Turinga y su corte en la época de Elisabeths, en Sankt Ellsabeth, pp. 38-44; Wilhelm MAURER, „Para la comprensión de Santa Elisabeth de Turinga», en Zeitschrift für Kirchengeschichte 65 (Revista para la historia eclesiástica). pp. 30-33. 
el año 1226, durante la ausencia de su esposo y en tiempos de gran sequía y hambre ella fue más lejos aún y convirtió la Wartburg en un hospital y un centro para actividades caritativas, según los nuevos principios religiosos ${ }^{43}$.

Ahora bien, las cortes seculares no podían funcionar durante largo tiempo como instituciones religiosas. Si las reinas santas querían dar forma material a la anticipación de la corte celestial, tenían que fundar sus propias comunidades. Para ello disponían de medios necesarios suficientes. La fundación de un hospital por parte de Elisabeth en Marburg actuó como ejemplo que pronto se imitaría (y cuya popularidad se mostró en las fundaciones similares por parte de santa Agnes, santa Hedwig así como por su nuera Ana ${ }^{44}$. En lo referente al estilo de vida de Elisabeth, debido a la severidad y dureza inquisitoriales de Konrad, tuvo que prescindir muy pronto de la compañía del círculo más íntimo de sus meninas. Con esto el punto principal de su carrera religiosa se desvió cada vez más en dirección al ejemplo mediterráneo de una inclusa ${ }^{45}$. Se podría añadir que un hospital era menos adecuado para las actividades religiosas de una reina que seguía teniendo contactos con los círculos cortesanos, que una comunidad religiosa que se estaba formando en su convento y alrededor suyo. De todas formas los conventos propios de mujeres de la realeza tenían una considerable tradición ya desde los tiempos de la alta Edad Media ${ }^{46}$.

Santa Hedwig fue la primera en tomar este camino cuando en el año 1202 fundó el convento de las cistercienses de Trebnitz para su hija Gertrudis, en el que ella misma pasó los últimos años de su vida y donde sus

${ }^{43}$ Libellus, pp. 18-20, 22-23, 31; cf. Raoul MANSELL, «Santită principesca e vita quotidiana in Elisabetta dUngheria: La testímonianza delle ancelles en Anelecta Tertil ordinis regslaris sancti Francisci, 18 (1985), pp. 23-45,

${ }^{44}$ Neumarki aprox. 1230, cf. Gortschal.K, St. Hedwig, pp. 132-134; Vita sanctae Hedwigis, pp. 546-547; para la fundación de un hospital por parte de Anna en el año 1253 en Breslau cf. KNoBucH, Herzogin Anna (La duquesa Anna), Anexo, pp. 11-23.

45 WerNER, «Santa Elisabeth y Conrado de Marburg», en Sanki Elisabeth, pp. 45-69; cf. Libellus, pp. 47-49; Anna BENVENUT PAPI, *Velut in sepulchro: cellane e recluse nella tradizione agiografica italianas, en Sofia Boesch Gajano - Lucia SEBstiant (eds.), Culto del santi, istituzioni e classi sociali in elà preindustriale, L'A quila/Roma, L.U. Japadre, 1984, pp. 365-455.

46 Sobre santa Radegunda y su convento en Poitiers véase Sabine GABE, «Radegundis: sancta, regina, ancilla. Sobre el ideal de santidad de los radegundisvitas de Fortunato y Baudonivias, en Francia, 16 (1989) pp. 1-30; sobre Santa Bathilda y el convento de Corbie ef. Roben Fon., *Tradition hagiographique et culte de Sainte Bathilde, reine des francs\%, en Académie des inscriptions et belles lettres. Comptes rendus des séances, 1975, pp. 369-384; sobre otras fundaciones reales similares en Inglaterra (Ely, Winchester) of. Susan Janet RIDYARD, The Royal Saints of Anglo-Scxon England. A study of West Saxan and East Anglian cults, Cambridge, Cambridge University Press, 1988, pp. 96-139, 176-210; sobre santa Mathilde y Quedlinburg: Patrick ConBer, Les saints Otroniens. Sainteté dynastique, sainteté royale et sainteté féminine autour de lan Mil (cuadernos adicionales de Francia, 15), Sigmaringen. Thorbecke, 1986, pp. 137-140. 
descendientes oficiaron de abadesas durante varias generaciones ${ }^{47}$. En el año 1234 Agnes de Bohemia buscó refugio «en compañía de las siete damas más nobles del reino, en la santa arca de la religión, tal como una paloma inocente huiría del diluvio que amenaza este mundo (saeculum $)^{48}$ y se fue al convento de las clarisas de Praga, fundado por ella misma, donde pasaría el siguiente medio sigio de su larga vida. Su hermana Ana, la nuera de santa Hedwig, siguió su ejemplo cuando enviudó, y fundó un convento de clarisas en Breslau en el año $1257^{49}$. En lo que respecta a las restantes princesas polacas, Salomea, p.ej., entró en un convento de clarisas en Zawichost, que su hermano Boleslaus había fundado para ella. Su cuñada Kunigunde fundo en el año 1279 otro convento en Sandecz para sí misma, donde su enviudada hermana Yolanda le hizo compañía hasta que también fundó un convento de clarisas en Gniezno en el año $1292^{50}$.

Santa Margarita recibió de sus padres su propia comunidad (que ya hemos conocido un poco): primero llegó a un «parvularion real-religioso en el convento Catalina de Veszprém, donde recibió, junto a una docena de oblatae aristocráticas, su educación religiosa. En los años siguientes a 1240, o sea cuando se fundó la que sería posteriormente la capital en el Schloßberg de Buda, se construyó en la vecina Isla de los Conejos en el Danubio un convento de dominicas para la princesa. En el año 1253 Margarita se mudó, junto a dieciocho monjas de Veszprém, a este convento y pronto tendria la compañia de muchas vírgenes y viudas aristocráticas $^{51}$. En los protocolos de canonización encontramos las declaraciones de cuarenta de las setenta monjas que, como se sabe, residían allí. Tres de ellas eran princesas reales como la misma Margarita, dieciséis procedían de los círculos más altos de la aristocracia (p.ej. la viuda y la hija de un antiguo conde palatino $o$ algunos miembros del poderoso clan aristocrático de los Csák), y otras dieciséis procedían, como se puede suponer, de familias de la nobleza ${ }^{32}$. De esta forma las reinas y princesas religiosas tenían a su alrededor una verdadera corte y su convento se con-

${ }^{47}$ Ewald WALTER, aEl valor hístórico de la fuente no documentada más vieja sobre la vida de santa Hedwig y sobre la fundación de la abadía cisterciense Trebnitz de la pluma de Caesarius von Heisterbachw, en Bernhard Srasinwsks (ed.), Beisrige zur Schlesischen Kirchengeschichte, Gedenkschrift für Kurt Engelbert (Contribuciones para la historia eclesiástica de Silesia, un memoríndum para Kurt Engelbert), Köln/Wien, Bōhlau, 1969, pp. 76-170; sobre las abadesas ef. GotrschaLK: Santa Hedwig, p. 223.

48 Vyskocil, Legenda, pp. 106-107; Helena Soukupová, Anezsky kláster v Praze, Pragea. Odeon, 1989.

${ }^{49} \mathrm{KNoBL} . \mathrm{CH}$, Herogin Anna (La Duquesa Anna), anexo.

${ }^{50} \mathrm{Cf}$. Wrrozumski, aLa sainteté des femmes\%, en Vita sanctae Kungae, pp. 699-702.

${ }^{51}$ KIRALY, Arpdidházi Szent Margit, pp، 49-77.

${ }^{52}$ MRV, pp. 165-284; Elmemér LovAs, Arpadházi Boldog Margit elete, Budapest, Szent István Társulat, 1940, pp. 111 y $\mathrm{ss.}$ 
virtió gracias a las generosas donaciones de sus parientes rápidamente en una de las instituciones eclesiásticas más ricas de Hungría ${ }^{53}$.

Leyendo la primera de las leyendas sobre Margarita (probablemente escrita por su confesor el padre Marcellus ${ }^{54}$ y las declaraciones que hicieron las cohermanas de Margarita en su canonización, se nos descubre una imagen fascinante que ilumina las simbólicas contradicciones entre la vida cotidiana de una corte mundana dominada por los hombres y su equivalente «celestial» dominado por las mujeres. Los ejercicios ascéticos de Margarita (aunque muestren numerosos paralelos con una religiosidad femenina en el siglo XII, marcada por una automortificación y apasionada espiritualidad eucarística, en la que el punto central es el «novio celestial», el Cristo que sufre y ama ${ }^{55}$ representan en este contexto sobre todo la crítica demostrativa del estilo de vida cortesana. Margarita goza llevando los vestidos bonitos que recibe de sus padres para los trabajos más sucios y ordinarios; rechaza las exquisiteces culinarias que su familia le ofrece; emplea el dinero que recibe de sus padres como limosna para los pobres y para el apoyo de instituciones eclesiásticas; insiste en hacer los trabajos más ordinarios de los sirvientes del convento (p.ej. la limpieza de las letrinas o destripar los animales muertos). «Cuanto más destacaba su origen noble entre las otras, tanto más se esforzaba en mostrarse la más humilde de todas ${ }^{56}$, podemos leer en su leyenda.

Pero tal transformación simbólica no significa lo mismo que una renuncia total a toda clase de poder. Muy al contrario, se convierte en una nueva base de poder, es decir, en relación con el prestigio de lo sobrenatural. La milagrosa Margarita que sabía profetizar y leer los pensamientos, cuyo cuerpo brillaba en una luz luminosa antes de ser fustigada por sus cohermanas ${ }^{57}$, que, como explicaba en mis primeros ejemplos, castigaba a sus enemigos o a aquellos que dudaban de sus palabras con milagros vengadores (otras princesas santas explicaron también similares milagros vengadores dirigidos contra sus coher-

53 Lovas, Arpddházi Boldog Margit, pp. 120-127.

54 Vita beate Margarite; se atribuye a Elemér Lovas, *Arpádházi B. Margit elsó életrajzának irója-Marcellus» (ef, nota 7), criticado por F. CALLAEY, Inquisitio iussu S.D.N. Pii papae XII peracta de vita $b$. Margaritac ab Hungaria sanctimonialis Ordinis Praedicatorum deque culto ei praestitio, S. Rituum Congreg., Sectio Historica 50, Ciudad del Vaticano 1943, p. XxIV: también György Györffy ha intentado refutar esta adjudicación (en: Tibor NAGY, György GYORFFY, Lászlo Gerrvica (eds.), Budapest tönénete az éskonól az Arpás-kor végég. Budapest, 1973, pp. 342-343).

55 Simone RorsIn, Lhagiographie cistercienne dans le diocèse de Liège au XIIle siècle, Lovaina/Bruselas, 1947. VAUCHEZ, La sainteté, pp. 402-410, 427-448; Carolyne W AL.KER BYNuM, Holy Feast and Holy Fast. The Religious Significance of Food to Medieval Women, Berkeley/Los Angeles, University of California Press, 1987; idem, Fragmentation and Redemption, Essays on Gender and the Human Body in Medieval Religion, Nueva York, Zone Books, 1991: Rudolph Bell: Holy Anorexia, Chicago-Londres, The University of Chicago Press, 1985.

56 Vita beate Margarite, p. 19.

57 MRV, p. 245. 
manas), esta princesa que se degradaba a sí misma disponía efectivamente de un poder sobrenatural mucho más grande que el de las princesas en general; ella podía emplearlo también fuera de los muros de su «corte celestial». En total se defendió tres veces con éxito contra los intentos de sus padres de sacarla del convento y casarla con ventaja para la dinastía. El que estas historias, contrariamente a los conocidos y similares «topoi» hagiográficos, tengan un fundamento evidentemente garantizado queda plasmado en el hecho de que el rey Béla IV, después del último de estos intentos, privó para siempre a las dominicas, que en todos estos conflictos siempre habían estado del lado de Margarita, de su patrocinio que desde entonces fue dado a los franciscanos ${ }^{58}$. Solamente este nuevo poder de Margarita, que le concedía un derecho poco común a la autodeterminación, puede explicar su independencia.

El prestigio político de las princesas y reinas santas queda plasmado también en las frecuentes intervenciones de Hedwig en cuestiones de jurisdicción, así como en la correspondencia política de Agnes de Bohemia que finalmente llevó a un conflicto político abierto con el rey Przemysl Ottokar II, quien prohibió su intervención en las relaciones de Bohemia con la corte papal ${ }^{59}$. La nueva posición de las princesas les confería el derecho de intervenir en disputas familiares. Cuando el rey bohemio Wenzel I en el año 1248 tenía que volver a conquistar la ciudad de Praga levantando el cerco de su rebelde hijo (y sucesor) Przemysl Ottokar II, se llegó a la reconciliación por mediación de Agnes en su convento, donde se dejó coronar nuevamente como rey el día de la Ascensión ${ }^{60}$. Un acontecimiento similar tuvo lugar en el año 1266 en Hungría cuando, probablemente gracias a la intervención de Margarita, se firmó un contrato de paz en la Isla de Margarita entre Béla IV y su hijo Esteban V, el kjoven rey s enemigo ${ }^{61}$. Un ejemplo posterior: la religiosa Elisabeth von Töss, la última princesa de los arpades, siempre fue llamada (a pesar de que no tenía ninguna influencia politica) Kungin Elsbet por sus hermanas dominicas en el convento, y fuera del convento fue saludada como una reina en el exilio ${ }^{62}$.

$\mathrm{La}$ influencia creciente de las princesas santas naturalmente tuvo como consecuencia que también sus confesores cistercienses, dominicos o franciscanos tuvieran cada vez más poder ${ }^{63}$. Incluso se podría decir que las vír-

${ }^{58}$ Vita beate Margarite, pp. 23-24: Erik FOGEDI, *La formation des villes et les ordres mendiants en Hongries, en Annales E.S.C. 25 (1970), pp. 966-987.

${ }^{59}$ Gortschal K, Sankt Hedwig. pp. 167-180; György Bal_anY1, «Csehországi Boldog Agnesw, en Regnum I (1938-1939), pp. 137-168.

${ }^{60}$ FassBinder, Die Selige Agnes (Santa Agnes), pp. 125-130.

${ }^{61}$ Gyula Patzer, A magyar nemzet törtenete az Arpádhazi kiralyak alatt, Budapest, Athenaeum, 1899 , t. It. p. 261.

62 VETTER, Das Leben (La Vida), pp. 103-104.

${ }^{63}$ WERNER: «Santa Elisabeth y Konrad de Marburgn, Vita sanctae Hedvigis, p. 531; WALTER. Studien (Estudios), pp. 46-66; John COAKI.EY, $\alpha$ Friars as confidants of Holy Women in Medieval Dominican Hagiographys, en BLUMENFEL-Kosinsk, Renate -SzE1., Timea (eds.), Images of Sainthood in Medieval Europe, Ithaca/Londres, Cornell University Press, 1991, pp. 222-245. 
genes aristocráticas bien controladas y explotadas como una especie de médium, actuaban exactamente según las instrucciones de sus confesores. De esta forma contribuyeron en efecto a disciplinar los primeros brotes aún débiles de una cultura cortesana en Europa central y a llenarla de contenidos religiosos. De forma parecida, en otras regiones la iglesia había podido apoyarse en la alta Edad Media, en el papel de conversoras de las esposas ${ }^{64}$; ahora se usaba hábilmente a las princesas de las órdenes de monjas mendicantes para asegurarles la misma influencia política en Europa central que en otras regiones, p.ej. en las ciudades de Italia habían ganado con medios muy diferentes.

Como comparación quisiera mencionar brevemente algunos ejemplos italianos - desde santa Clara o Ángela de Foligno hasta santa Catalina de Siena- para poder ilustrar también que este tipo de Charismas religiosos femeninos ${ }^{65}$ podía alcanzarse con diferentes medios. Las místicas burguesas italianas (que también tenían más de un talentoso confesor/empresario ${ }^{66}$ a sus espaldas) descubrieron pronto las correspondientes formas simbólicas y religiosas para llegar a tener influencia política en el ambiente urbano de las ciudades italianas. Esto implicaba desde intervenciones proféticas en las plazas urbanas (Rosa de Viterbo ${ }^{67}$ ) y discusiones anti-herejes (Clara de Montefalco ${ }^{68}$ ), intentos de mediación en la disputa de partidos en una ciudad (Margarita de Cortona ${ }^{69}$ ) y disuasión de una amenaza de invasión del enemigo (Clara de Assís ${ }^{70}$, hasta la correspondencia y los encuentros con los más altos dignatarios eclesiásticos y seculares de su tiempo: papas, emperadores y reyes, en el caso de Catalina de Siena ${ }^{71}$. Con esto, los confesores pertenecientes a las órdenes mendicantes pronto serían relegados a sim-

64 I Kor 7:14, citado por Beda Venerabius, Historia Ecclesiastica gentis Anglorum, ed. C. Pu ummer, Oxford, 1896, 19612, t. II, pp. 10-11: cf. también Godefroid KuRTH: Sainte Clo. tilde, Paris, 1898, pp. 7-13.

${ }^{65}$ Sobre el concepto Charisma, especialmente en relación con la santidad, cf. Wolfgang Lipp, Stigma und Charisma. Ober soziales Grenzverhalten (Estigma y carisma. Sobre comportamiento social límite), Berlín, Dietrich Reimer, 1985, pp. 250-255.

${ }^{65}$ Aquí hay una lista corta: a la relación arquetípica entre el santo Francisco y santa Clara siguieron Umiliana dei Cerchi y fra Michele; Angela da Foligno y Frate Arnaldo: Margherita da Cortona y fra Giunta Bevignati; Clara de Montefalco y fra Berengario di S. Africano: Agnese da Montepulciano, Catalina de Siena y Raimundo da Capua.

${ }^{67}$ Giuseppe ABATE, $\propto$ Santa Rosa di Viterbo, Terziaria Francescana (1233-1251). Fonti storiche della vita e loro revísione criticas, en Miscellanea Francescana, 52, fasc. i-ii (1952), pp. 112-278.

${ }_{68}$ Enrico MANeSto (ed.), Il processo di canonizzazione di Chiara da Montefalco, Perusa Florencia, Regione dell'Umbria/«La Nuova Italia» Editrice, 1984; pp. 57-59, 142-144, 224-227. 287-291.

${ }^{60}$ Franco Cardent, a Agiografia e politica: Margherita da Cortona e le vicende di una città inquietaw, en Studi Francescani, 1979 (76), pp. 133-135.

${ }^{70}$ GRAU, Leben und Schriften (Vida y escritos), pp. 21-23, 30-33.

71 Peter Dinzz_.BACHER, «La gestión política de las místicas en iglesia y estado: Hildegard, Brigitta, Catalinan, en fdem - Dieter R. BAUER, Religióse Frauenbewegung und mystische 
ples escribientes o seeretarios y fueron víctimas de burlas debido a su falta de capacidades ${ }^{72}$. Estas santas femeninas se sobreponfan audazmente a todas las disposiciones y consejos que tenían como objetivo la moderación, se lanzaban con salvaje pasión a hacer ejercicios ascéticos cada vez más impresionantes, con los que algunas se mortificaron o ayunaron hasta la muerte (Catalina de Siena) - y todo con la conciencia de convertirse en una novia de Cristo aún más perfecta.

Las santas femeninas de la baja Edad Media consiguieron realmente un prestigio impresionante por su poder carismático y místico. Su primera generación en Europa central, las princesas santas, necesitó todavía de la imagen «corte celestial» y el prestigio del linaje real. Con ello consiguieron poner un sillar para la emancipación religiosa de las mujeres en la baja Edad Media. En las ciudades italianas no existian ni la descendencia real ni la «corte celestial»; en cambio aquí se desarrolló en el siglo xIV el poder del misticismo político, basado en ejercicios ascéticos espectaculares y en un ayuno estricto, pero también en manifestaciones singulares y sabias y en la atrevida imaginación de la pronta realización de la «Jerusalén celeste» "73. En el siglo XV, el poder sobrenatural de las santas femeninas, como el ejemplo de Juana de Orléans ${ }^{74}$, era ya asequible incluso para las hijas de campesinos. Y este poder era capaz de salvar el reino de Francia, no sólo con hagiográficos «milagros de batalla ${ }^{75}$, sino con victorias militares absolutamente reales.

En este momento voy a dejar a las princesas santas y voy a volver al tema de la brujería. Desde mi punto de vista, la notable ascención de las santas femeninas en la baja Edad Media, la manifiesta coincidencia con las imágenes de ideal religioso de entonces, de quien serviría como médium para la irrupción de poderes divinos y sobrenaturales en la existencia cotidiana y, en particular, la forma en la que conseguían transformar sus capacidades sobrenaturales en un poder político, llevó a una especie de emancipación femenina, pero al mismo tiempo despertó seguramente temor y miedo. Las reacciones ambivalentes a estas santas femeninas de mucha influencia han

Frömmigkeit im Mittelalter (El movimiento religioso de las mujeres y la religiosidad mística en la Edad Media), Colonia/Viena, Böhlau, 1988, pp. 265-302.

72 De esto informa p.ej, frate Arnaldo, el cescribientes de las visiones de Angela da Foligno (véase M. Faloci PulignANi, Lautobiografia e gli seritti della beata Angela da Foligno pubblicati e annotati da un codice sublacense, Città di Castello, 1932, pp. 28, 40-42.

73 Vitus Cortonensis, Vita beatae Hamilianae de Cerchis, AA SS IV Maii, p. 389; CARDINI, «Agiografia e politican, pp. 130-131; Anna BENVENUT PAF, eMargherita Filia Jerusalem. Santa Margherita da Cortona ed il superamento mistico della crociata», en Franco CARDINI (ed.), Toscana e Terrasanta nel medioevo, Florencia, 1982, pp. 117-138.

${ }_{74}$ Marina WARNER: Joan of Arc: The Image of Female Heroism, Nueva York, Knopf, 1981.

${ }^{75} \mathrm{Cf}$. Frantisek Graus, « El santo como ayudante en la batalla - Sobre la nacionalización de un relato sobre un milagro en la cronística medieval», en Fesischrift für Helmut Beumann zum 65. Geburtstag, Sigmaringen, Thorbecke, 1977, pp. 330-348. 
contribuido, sin duda, a que la imagen terrible de las brujas existente en la alta Edad Moderna fuese sustancialmente femenina ${ }^{76}$. Esto se muestra sobre todo en Malleus Maleficarum (donde los autores hacen de la pregunta « ¿ cómo es que sobre todo las mujeres son adictas de la superstición mala?» un estudio casuístico ${ }^{77}$ ), pero también en el hecho de que sobre todo las mujeres cayesen victimas de las cazas de brujas.

Esta tesis se ve apoyada si se considera la ambigüedad fundamental que surgió desde el siglo xv en el enjuiciamiento de las nuevas místicas y santas femeninas y que culminó en la pregunta: ¿es realmente una santa o quizás sólo sea una bruja? Los teólogos ya tuvieron sus dudas en el caso de Catalina de Siena que hubo de justificarse ante una comisión de inquisidores de los dominicos contra el cargo de herejía, y posteriormente sólo pudo defenderse contra las sospechas en torno a su maravilloso don de sobrevivir a pesar de los ayunos estrictos (muchos sospecharon trucos diabólicos) accediendo a tomar alimentos cada día en público (pero los vomitaba inmediatamente después) ${ }^{78}$. Otro ejemplo instructivo para esta ambigüedad fue la famosa investigación de las visiones de Juana de Orléans en el año 1430: ¿quién habló a Juana: santa Catalina de Alejandría, santa Margarita de Antioquía y san Miguel, como ella afirmaba, o fueron más bien «espíritus malos y diabólicos»: Belial, Satanás y Behemoths, como suponían sus jueces??

La posición ambivalente de las santas femeninas en la baja Edad Media entre Dios y el diablo se reforzó sin duda aún más a través de los informes cada vez más detallados, en los que ellas mismas o sus hagiógrafos describían sus tentaciones diabólicas heroicamente vencidas. Benvenuta Bojani (1255-1292), del norte de Italia, fue atormentada por diablos que penetraron en su habitación en la figura de un joven apuesto o, en otras ocasiones, como monjes ambulantes e intentaron seducirlas ${ }^{80}$. Francisca Romana (1382-1440) sufría de numerosos demonios sexuales que se le aparecían cada noche en figuras de hombres, mujeres y niños desnudos y que querían

\footnotetext{
76 Sobre la popularidad de la santidad femenina en los siglos xil y xiv cf. VAUCHEZ, La saintete, pp. 439-446; Brnum, Holy Feast and Holy Fast, pp. 13-29; Beit, Holy Anorexia, passim. Sobre la contrarreacción de la diabolización, cf. Jeffrey BURTON RUSSEL. Witcheraft in the Middle Ages, Ithaca/Londres, Cornell University Press, 1972, p. 284; BynuM, Holy Feast and Holy Fast, p. 316, idem, Fragmentation, p. 215.

77 Jakob SPRENGER - Heinrich INSTTTORIS, Der Hexenhammer (El martillo de las brujas), traducido por J.W.R. Schmidt, 1906, 1980, Cf. Peter SEGt. (ed.), Der Hexenhammer, Entsteluang und Umfeld des Malleus Maleficarum von 1487 (El martillo de las brujas, origen y entomo del Malleus Maleficarum del 1487), Colonia-Viena, Böhlau, 1988.

78 Timoteo M. CENIE: «Un processo inventato di sana piantas, en: T. CENTI (ed.), S. Caterina fra i dottori della chiesa, Florencia 1970, pp. 39-56; cf. Bell, Holy Anorexia, pp. 23-25, 194.

79 William A. Christian, Jr: Apparitions in Late Medieval and Renaissance Spain, Princeton, Princeton University Press, 1981, pp. 188-191.

${ }^{80}$ BEL.: Holy Anorexia, p. 128.
} 
inducirla a orgías sodomíticas ${ }^{81}$. ¿ Hasta cuándo podían estas místicas convencer a su auditorio de que se habian resistido a tales tentaciones con éxito? La mayoría de las pretendidas brujas finalmente habían, según las acusaciones y sus propias confesiones, acordado pactos con el diablo, a pesar de insistir en que no lo habían hecho voluntariamente.

Colomba de Rieti (1467-1510) fue probablemente la primera santa en la que esta ambivalencia literalmente explotó cuando se le imputó que:

no era ninguna santa que ni come ni bebe, sino más bien insaciable y muchas cosas más [...], ella es una bruja. En su habitación encontramos bajo su cama una colección de huesos y una cesta llena de hostias que había vomitado. Su confesor mismo es un mago que tiene la llave de todo esto en su $\operatorname{mano}^{82}$.

Las mismas acusaciones fueron formuladas contra varias otras mujeres que pretendian la santidad, p.ej. contra Catalina de Racconigi (+1547), Domenica dal Paradiso (+1553), Orsola Benincasa (1547-1618) y Giulia di Marco (siglo XV1) ${ }^{83}$. Cada vez fue más fácil llevar a las místicas populares como siervas del diablo ante la Inquisición.

Pero todavía hay otras numerosas coincidencias aún más transcendentes entre el culto a las santas y la brujería, aparte del doble concepto antitético de «santa» $y$ «bruja», que parece dominar el discurso actual. Como representantes de dos polos opuestos del universo mucho más grande de la mágica imaginación religiosa de ciertas personas con dones sobrenaturales, nos ofrecen una serie de confusas correlaciones históricas y morfológicas. Un breve resumen de estas dos grandes áreas podría considerar las apariciones que nos ocupan aqui, bajo otro aspecto.

Peter Brown ha explicado de qué forma tuvo lugar, en el siglo Iv en el Imperio Romano, la primera ola de caza de brujas de la que tenemos conocimiento dentro de la historia europea, causada por la aparición de la figura del santo. El entonces recién surgido culto a los santos facilitaba «una explicación para la mala suerte, que no sólo abarcaban las apariciones atribuidas a la magia y brujería, sino al mismo tiempo daba al individuo las

${ }^{81}$ BEL: Holy Anorexia, p. 138.

82 BEL: Holy Anorexia, p. 156

${ }^{83}$ Gabriella ZARRI, \&Le sante vive. Per una tipologia della santita femminile nel primo Cinquecentow, en Annali dell'7stituto Storico Italo-germanico in Trento, 6 (1980), pp. 371-445; idem, Le sante vive. Profezie di corte e devozione femminile tra '400 e '500, Turín, Rosenberg \& Sellier, 1990; BEL. Holy Anorexia, pp. 160-166: Jean-Michel SALlmanN: «La sainteté mystique féminine a Naples», en BOESCH GAJANO - SEBAstiani, Culto dei santi, pp. 681-702: Luisa Ciammitti: «Una santa di meno. Storia di Angela Mellini, cucitrice bolognese (1667-17..)»: Quaderni Storici, 14 (1979), pp. 603-639. No me fue posible el acceso al estudio de Peter DiNZFLAACHER, «Sante o streghe? Alcuni casi del tardo Medioevos, que se publicará junto con el material sobre el seminario de Udine en 1990 Santità vera, santita finta. 
armas relativamente efectivas contra sus contrincantes sobrehumanos ${ }^{84}$. Con sus espectaculares exorcismos practicados con la ayuda del «poder que les fue dadom, los santos de la antigüedad tardía consiguieron no sólo quitar importancia a los magos, sino que ya no se reaccionara a una desgracia buscando el hipotético enemigo dentro de la comunidad (un «traidor dentro de las propias paredes», como Philip Mayer llamaba a las brujas ${ }^{85}$ y atribuyendo la culpa a personas humanas, sino haciendo responsable al diablo y a los demonios que actuaban a sus órdenes. (Aquí se conjugan naturalmente también los pecados humanos, aunque más bien en forma del pecado original o de las continuas debilidades de las personas que indujeron a Dios a permitir al diablo una esfera de actuación para seducir o atormentar a aquellos que se lo merecían.) Bajo este punto de vista se relegan ampliamente las «incómodas» facultades mágicas de los magos o las brujas, cuya existencia y desmoralización no se cuestiona, a un segundo plano en la esfera de los infieles, mientras los cristianos se unen bajo la protección de sus santos patronos. Aparte de esto, los santos y sus milagros eran mucho más efectivos, como intentó comprobar san Agustín ${ }^{86}$, que el «embuste de los espíritus malos» y las ridículas y malvadas actividades de sus seguidores.

A pesar de ello, las prácticas de la magia, hechicería y brujería (cuya diferenciación contextual se desdibujaba cada vez más en el marco de la fusión de diferentes contenidos de culto pagano en la alta Edad Media ${ }^{87}$ ) no perdieron en absoluto importancia tan rápida y ampliamente como parecía al comienzo del siglo rv o v. En los siguientes cinco hasta seis siglos y en el transcurso de la progresiva conversión de nuevos pueblos, estos contenidos tuvieron que ser combatidos por la iglesia. Los exponentes más importantes de esta lucha fueron también aquí los santos. Los santos conversores (como san Martín, san Cuthbert o san Bonifacio) tuvieron que hacer milagros repetidamente para demostrar que sus poderes mágicos (que incluso después de sus muertes siguieron siendo efectivos a través de sus reliquias) eran superiores a los de los brujos paganos y a sus conjuras y amuletos y que

${ }^{84}$ Peter BRown, $*$ Sorcery, Demons and the Rise of Christianity from late Antiquity into the Middle Ages», en Mary Dougl.As (ed.), Witcheraft Confessions and Accusations, Londres, Tavistock, 1970, p. 28.

${ }_{85}$ Philip MAYER, «Witchesw, en Max MARwick (ed.), Witcheraft and Sorcery. Selected Readings, Harmondsworth. Penguin, 1970, pp, 45-64.

${ }_{86}$ Benedicta WARD, Miracles and the Medieval Mind, Londres, Scolar, 1982, pp. 9-10; Peter Brown, The Cult of Saints. Its Rise and Function in Latin Christianity, Chicago, The University of Chicago Press, 1981, pp. 27-29, $38,78$.

${ }^{87} \mathrm{Cf}$. Norman COHN, Europe's Inner Demons. An Enquiry Inspired by the Great Witch-Hunt, Nueva York, Basic Books, 1975; A.A. BARB, «The Survival of Magic Arts», en Arnaldo MoMigliano (ed.). The Conflict between Paganism and Christianity in the Fourth Century, Oxford, 1963, pp, 100-125; Richard KIECKHEFER, Magic in the Middle Ages, Cambridge, Cambridge University Press, 1989; Valerie I.J. FunT, The Rise of Magic in Early Medieval Europe. Princeton, Princeton University Press, 1991. 
constitufan un antídoto mucho más eficaz contra los mismos problemas ${ }^{88}$. Esto llevó (en un marco más amplio de lo que Keith Thomas llamó la «magia de la iglesia medieval ${ }^{89}$ ) a otras correlaciones entre las imaginaciones de poderes y técnicas mágicas de los santos milagrosos y las de los hechiceros, brujos y charlatanes populares. El gran número de milagros de castigo en las colecciones de milagros de la Alta Edad Media, p.ej. los de Gregorio de Tours, debe considerarse como una de las consecuencias de esta confrontación del culto a los santos con las rivalizantes imaginaciones mágicas populares. Se podría encontrar aspectos similares en las extrañas prácticas de «coacción» y «mal traton de las reliquias, tal como lo analizó recientemente Patrick Geary ${ }^{90}$; en aquellos casos se maltrató las reliquias física y litúrgicamente y de forma claramente mágica para provocar el milagro deseado (tratándose aquí también frecuentemente de milagros de castigo, p.ej.., el castigo a un señor que se había apropiado del patrimonio de un convento). También estas prácticas muestran claros paralelos con las más simples técnicas populares en la baja Edad Media: el trato de las supuestas brujas que consistia en intentar forzarlas a retractarse del embrujo pronunciado, amenazándolas, maltratándolas físicamente 0 , con la ayuda de un especialista popular en contraagresiones mágicas, intentar dañarlas simbólicamente.

La duradera presencia y el desarrollo posterior de la fe en las brujas y los magos en la Edad Media es una historia oscura, difícil de seguir. Una recopilación cuidadosa de la gran cantidad de colecciones de milagros, en particular con respecto a los milagros de castigo y la curación de obsesionados y embrujados por los santos, ampliaría nuestro conocimiento, pero por la situación del material no parece posible recibir mucha más información de la que ya disponemos según las investigaciones de J.B. Russell, Norman Cohn, Richard Kieckhefer, Edward Peters y Carlo Ginzburg 91 .

${ }^{88} \mathrm{Cf}$. WARD, Miracles, pp. 10-13, 56-65; GuREvich, Medieval popular culture, pp. 39-76; Peter DINZz BACHER, eLa lucha de los santos contra los demonioss, en Santi e demoni nell Alto Medioevo occidentale (siglos V-XI) XXXVI Semana de Estudio del Centro italiano de estudios sobre la alta Edad Media, Spoleto, 7-13 abril 1988, Spoleto, 1989, pp. 647-695.

${ }^{89}$ Keith ThomAs, Religion and the Decline of Magic. Studies in popular beliefs in sixteenth and seventeenth century England, Londres, Routledge \& Kegan Paul, 1971, pp. 25-50; C. Grant Looms, White Magic. An Introduction to the Folklore of Christian Legend, Cambridge, Mass., The Medieval Academy of America, 1948.

${ }^{90}$ Patrick J. Geary, a La coercition des saints dans la pratique religieuse médiévales, en $\mathrm{La}$ culture populaire au Moyen Âge, IV Colloque de IIInstitut d'études médievales de IUniv. de Montréal (Montréal, 1977), pp. 149-177; idem, kL humiliation des saints», Annales E.S.C. 34 (1979), pp, 27-42.

${ }_{91}$ RUSSEL. Witcheraft, CoHv, Europe's Inner Demons; Richard KIECKHFrR, European Witch Trials: Their Foundations in Popular and Learned Culture, 1300-1500, Berkeley/Los Angeles, Califomia University Press, 1976; Edward Perters, The magician, the witch and the law, Filadelfia University of Pennsylvania Press, 1978; Carlo GinzBura: Hexensabbat, Berlín, Wagenbach, 1990. 
Por lo menos existe la posibilidad de investigar detalladamente el tema que da título a este artículo. Quisiera hacer unos breves comentarios.

Si consideramos el desarrollo religioso en la Europa cristiana en el transcurso del largo periodo desde aproximadamente el siglo XII-XIII hasta el siglo XVII-XVII y buscamos amplias fuentes históricas para el tema de la fe popular en torno a personas que disponen de poderes sobrenaturales, entonces se nos ofrecen dos clases diferentes de fuentes. Por un lado, tenemos las descripciones de milagros de los llamados «santos modernos» que, según las determinaciones del procedimiento de canonización, institucionalizado ${ }^{92}$ desde el siglo XIII, podían considerarse susceptibles de un nuevo culto. Se podía ampliar estas descripciones con los apuntes menos oficiales sobre los milagros dentro de un marco de cultos locales como también con los indices de milagros en los diferentes lugares de peregrinación ${ }^{93}$. Como segundo tipo de fuente podemos citar la documentación de los procesos de brujas de la alta Edad Moderna, en particular aquellos párrafos que sólo recientemente han ocupado el centro de la investigación histórica ${ }^{94}$ : las más de mil descripciones de maleficia de los testigos de los procesos de brujas $\rightarrow$ o de personas que supuestamente habían sido embrujadas o de sus parientes o sus amigos que tuvieron que declarar.

Aunque naturalmente hay que ser escéptico ya que una comparación de los dos tipos de fuentes parece de gran vuelo, las sorprendentes coincidencias que resultan son una gran tentación. En los dos casos el problema es en gran parte el mismo: se trata de definir las dotes sobrenaturales de una persona determinada con la ayuda de la combinación de «saber/podern, la cual fue descrita por Michel Foucault como muy característica para la Edad Media, es decir, la de una investigación inquisitorial o judicial ${ }^{95}$. En los dos casos, la investigación tiene lugar bajo unas circunstancias que en parte proporcionan las pruebas que tenían que confirmar sus suposiciones iniciales. En los dos casos tratamos con personas que cuentan historias, o sea, construcciones narrativas sobre sucesos mágicos de forma milagrosa 0 desgraciada que les hayan pasado a ellos mismos o a personas conocidas. En contraste con las (no menos interesantes, pero completamente diferentes) tradiciones académicas de la hagiografía o - en el otro extremo- de la demoniología nos confrontamos aquí no sólo con una multitud de imaginaciones de fe extrañas, sino que también podemos ver claramente de qué

${ }^{92}$ E.W. KEMP: Canonization and Authority in the Western Church, Oxford, 1948: VAUCHEZ, La sainteté, pp. 25-119.

${ }_{93} \mathrm{Cf}$. StonL. L'homme et le miracle; Ward, Miracles.

94 Alan MACFARL ANE, Witcheraft in Tudor and Stuart England. A regional and Compararive Study, Nueva York/Evanston, 1970; Thomas, Religion and the Decline of Magic.

${ }^{95}$ Michel Foucault, Discipline and Punish. The Birth of the Prison, traducido por Alan Sheridan, Nueva York, Vintage Books, 1979, pp. 225-228; idem, Résume des cours, 1970-1982, Paris: Julliard, 1989, pp. 21-23. 
forma los temores mágicos están empotrados en los sucesos cotidianos, en conflictos familiares, y cómo determinadas personas que ocupan el punto central personifican un carisma maravilloso y mágico - así como si «un aspecto constantemente presente, aunque explosivo de la vida social en ocasiones estallara en llamas», para citar a Clifford Geertz ${ }^{96}$.

André Vauchez y Pierre-André Sigal, al examinar colecciones de relatos de los más grandes milagros de los siglos XII al XIV, encontraron una cantidad limitada de tipos de milagros y una sucesión característica de unidades morfológicas ${ }^{97}$. Quisiera caracterizar esta cadena morfológica con las siguientes unidades: la descripción de un desastre junto con posibles alusiones a un crimen o un error en el que se basa este desastre; la invocación del o de los santos correspondientes con la promesa de una recompensa; la peregrinación al relicario del o de los santos correspondientes, acaso con sacrificios adecuados para este estatus «de umbral» ${ }^{98}$; el drama de la curación o de la anulación de otro desastre con sus específicos parámetros espaciales, cronológicos o rituales; la compensación del o de los santos que se expresa a través de donaciones votivas. En la mayoría de los casos examinados los milagros pusieron en marcha todo un sistema de técnicas, prescripciones y reglas dinámicas que se tenían que seguir estrictamente. Pero lo que es aún más interesante: durante los tres siglos que fueron examinados se comprobó una sucesiva modificación de estas reglas y prescripciones. Desde las formas más bien arcaicas de una curación mediante contacto con las reliquias, echarse sobre ellas o andar alrededor de ellas hasta las formas más refinadas y generalizadas del efecto de la curación, que desde el momento del voto iba en aumento a medida que se acercaba uno a las relíquias, se efectúa una sucesiva transformación en el sentido de una «trivialización» del poder milagroso; finalmente tienen efecto también a larga distancia, directamente en el momento del voto, a través de la mediación de una imagen o también de sueños ${ }^{99}$.

Quiero resaltar que aquí no se trata de que un tipo «desarrollado de manera superior» hubiese sustituido las arcaicas formas primitivas: también éstas se han mantenido hasta nuestros días. Hablo de una transformación del peso de la frecuencia, que sólo pudo ser reconocida al examinar por principio una gran cantidad de todos los casos documentados.

Estimulados por todas estas investigaciones de los milagros medievales, hemos celebrado hace más o menos seis años en Budapest un workshop de etnógrafos e historiadores, en el cual se trataba de un proyecto de inves-

${ }^{96}$ Clifford GEERTz, $*$ Centers, kings and charisma: Reflections on the symbolics of powers, en idem: Local Knowledge, Further Essays in Interpretive Anthropology, Nueva York, Basic Books, 1983, p. 123.

${ }_{97}$ VAUCHEZ, La sainteté, pp. 519-557; StonL, L'homme et le miracle, passim.

${ }_{98} \mathrm{Cf}$. las obras de Victor TURNER, citadas en la nota 11.

99 Vauchiz, La sainteté, pp. 519-539. 
tigación similar a las descripciones de embrujamientos que se pueden seguir en los protocolos de los aproximadamente dos mil procesos de brujas documentados en Hungría (en el transcurso de las olas relativamente tardías de persecuciones de brujas entre 1560 y 1770). Este proyecto quería codificar y reciclar mediante un banco de datos por ordenador (KAEI $\Omega$ ), cada uno de los datos de las aproximadamente veinte mil descripciones de embrujamientos recogidas en estos procesos.

Para poder codificar un suceso tan oscuro y descrito de forma tan inexacta, hemos intentado desarrollar una idealizada secuencia morfológica que considera siete diferentes escalones o pasos de embrujamiento: 1) el conflicto de partida (entre brujas y sus víctimas); 2) la amenaza resultante de esto o la maldición; 3 ) la aparición física de la bruja cerca de su víctima (para dar efecto al embrujo, eso es, mediante saliva, miradas malignas, medicamento falso o una herramienta mágica oculta); 4) la experiencia visionaria de la aparición sobrenatural (pesadillas, secuestro de la víctima el sabbat); 5) el daño resultante del embrujamiento; 6) la diagnosis del embrujamiento (casi siempre con la ayuda de un diagnóstico profesional o de un ritual de adivinación); 7) los intentos de curación (que ocasionalmente se pedía también a las mismas brujas mediante amenazas, mal trato o el simple arreglo del daño: sin embargo, en otros casos los efectuaba el especialista).

Si se compara esta secuencia morfológica con la de los milagros, resulta fascinante la cantidad de paralelismos y similitudes. Aparte de las ya mencionadas, hay que resaltar que en los dos casos tratamos con tipos ideales de construcciones narrativas en las que puede haber numerosas omisiones. combinaciones y repeticiones. De ninguna manera debemos confundirlas con las descripciones de los sucesos reales —son (como lo interpreta Jeanne Favret-Saada después de un cuidadoso estudio ${ }^{100}$ ) reinterpretaciones posteriores y además amplificadas terapeúticamente de los verdaderos sucesos (una limitación que quizás sea válida también para las curaciones milagrosas). Ambas interpretaciones exigen la ayuda de un especialista en estas cosas (curanderos, sanadores o curas o hagiógrafos). Son la expresión de un intento desesperado de servirse del fondo de conocimientos disponible sobre cómo se ha de proceder con esta esfera de lo sobrenatural. Por todas estas razones obedecen forzosamente a una especie de «gramática» de lo sagrado - reglas que definen las condiciones, las técnicas, las personas, los parámetros espacio-temporales, las legalidades rituales y dinámicas, que hacen que un determinado hecho en un contexto dado se haga efectivo.

El estudio de esta fundamental gramática podría apoyarse en el material de los dos tipos de fuentes y formas de documentacion ya mencio-

100 Jeanne FAYrEt-SAADA, Les Mots, la mort, les sorts. La Sorcellerie dans le Bocage, París, Gallimard, 1977. 
nadas. Quizás se podría incluso desarrollar algunas tesis con respecto a su transformación. Así, un planteamiento fascinante podría ser p.ej. si podemos hacer constar, dentro de la fe en brujerías, un tipo similar de "espiritualización» como lo hemos observado en el contexto de los milagros en la baja Edad Media (un aumento de la participación relativa de formas sobrenaturales de descripciones de embrujamientos frente a formas más bien arcaicas que se basan en la cercanía física y el contacto con la bruja). Otro planteamiento más amplio levantaría otra vez el problema investigado por Keith Thomas ${ }^{101}$ de cómo se podría explicar que las acusaciones de brujería - y en general el miedo al embrujamiento y a la agresión mágica - tengan exactamente el mismo lugar en la Edad Moderna que el que ocupó en la Edad Media la benéfica y mágica función protectora de los santos.

Pero primero tenemos que esperar a los resultados de nuestra investigación de largo alcance. Sin embargo, quisiera mencionar aquí algo que, dicho de paso, nos lleva otra vez al punto de partida de nuestras reflexiones, o sea, a la santa princesa Margarita. En la Edad Media existían dos lugares santos en los alrededores de Buda - la isla de Santa Margarita (de cuyo poder milagroso ya hemos hablado al principio) y el monte del Santo Gellért, un obispo convertido en mártir en el siglo XI. Al comienzo de la alta Edad Moderna, o sea, durante la ocupación turca, estos dos cultos desaparecieron. Sin embargo, el último, el del monte Gellért, encontró una nueva importancia sagrada - se convirtió en el «Blocksberg» 102 húngaro, donde se supone se encontraban las brujas de todo el país para el $s a b b a t^{103}$ ). En el sentido metafórico este revés es directamente un ejemplo modelo para el desarrollo que he expuesto aquí.

101 Thomas, Religion and the Decline of Magic, pp. 51-78.

102 (N. del T.). El «Blocksbergø: monte alemán donde se reunían las monjas.

${ }^{103}$ Cf. mi estudio: all monte di San Gherardo e Fisola di Santa Margheritan, citado en los comentarios de la nota 9. 